\title{
Estado y perversión. Consideraciones sobre la técnica en psicoanálisis durante la revuelta social en Chile
}

\author{
State and Perversion. Considerations on Technique in \\ Psychoanalysis during the Social Revolt in Chile \\ Estado e perversão. Considerações sobre a técnica em \\ psicanálise durante a revolta social no Chile
}

Luis Felipe Revuelto*

\section{RESUMEN}

Este artículo propone reflexionar sobre ciertos fundamentos técnicos del psicoanálisis en un contexto de violencia políticoestatal en Chile desde octubre de 2019, ante ciertos elementos traumáticos de esta que son desmentidos por parte del Estado. Se reflexionará sobre la desmentida/denegación en psicoanálisis, para pensar, junto a esto, una política denegatoria en el campo de lo social, aquella que buscaría no dejar huellas de sus actos intentando borrarlos. Desde Aceituno, Davoine y Gaudillière, se pensará acerca de aquello que intenta ser borrado, buscará vías para inscribirse y así repensar cuestiones técnicas que posibiliten no denegar la historia que compartimos analista y paciente.

\begin{abstract}
This article proposes a reflection on certain technical foundations of psychoanalysis in a context of political-state violence in Chile since October 2019, in the face of certain traumatic elements that are denied by the State. It will reflect on refutation/ denial in psychoanalysis to think up a denial policy in the social realm, one that would seek to leave no trace of its acts by trying to erase them. From the perspective of Aceituno, Davoine and Gaudillière, the text will reflect on what is trying to be erased, looking for ways to register and thus rethink technical questions
\end{abstract}

Palabras clave: desmentida, política denegatoria, revuelta social, neutralidad, psicoanálisis.

Key words: Denied, denial policy, social revolt, neutrality, psychoanalysis.

\footnotetext{
* Psicólogo Universidad Alberto Hurtado. feliperevuelto@gmail.com
} 
that make it possible to not deny the story shared by the analyst and patient.

\section{RESUMO}

Este artigo propõe uma reflexão sobre certos fundamentos técni-

Palavras-chave:

cos da psicanálise em um contexto de violência político-estatal no Chile vivido desde outubro de 2019, diante de certos elementos traumáticos desta que são desmentidos por parte do Estado. O texto refletirá sobre o ato de desmentir/negar na psicanálise, para pensar, assim, em uma política de negação no campo social, desmentir, política de negação, revolta social, neutralidade, psicanálise. aquela que procuraria não deixar vestígios de seus atos tentando eliminá-los. Desde Aceituno, Davoine e Gaudillière, será analisado aquilo que se tenta apagar, serão buscadas vias para se registrar e, assim, repensar questões técnicas que permitam não negar a história que nós, analistas e pacientes, compartilhamos. 


\section{Elementos introductorios}

La denominada "revuelta social", en Chile, surge a partir del movimiento encabezado por estudiantes secundarios que, frente al anuncio de una nueva alza del precio del transporte público (Metro de Santiago) en 30 pesos chilenos ( 0,037 dólares) ( 24 horas, 2019), se manifiesta con masivas evasiones al pago del Metro de Santiago. Estos acontecimientos dieron lugar a la consigna "no son 30 pesos, son 30 años", aludiendo a los últimos 30 años desde el retorno de la democracia, periodo en el que se naturaliza y profundiza un sistema económico neoliberal implementado durante la dictadura militar entre 1973 y 1990.

Es, en este contexto, que a partir del 18 de octubre de 2019, irrumpen diferentes formas de protestas sociales que convocaron a una gran parte de la ciudadanía, la que clama, a través de distintos medios, todo tipo de demandas por una vida más digna, tales como redacción e implementación de una nueva Constitución, fin de las administradoras de fondos de pensiones (AFP), una mejoría al sistema de salud, tanto en su acceso como en la calidad, mejoras al transporte público, fin a la privatización del agua, educación de calidad y un equitativo acceso, por nombrar solo algunas. Todas aquellas demandas que nacen desde las vivencias de un sistema económico y político neoliberal, caracterizado por sostener y favorecer a los sectores más acomodados de la población, a consecuencia de mantener y profundizar la precariedad de la vida en los sectores más vulnerables del país. En este sentido, la consigna del neoliberalismo quedaría resumida, en palabras de Flisfisch (1982), "construid el mercado, así perezca la sociedad" (p. 21).

De este modo, es necesario elucidar, siguiendo a Salazar (2013), que los proyectos contrarrevolucionarios liberales luego de la Guerra Fría buscaban erradicar de raíz todas las políticas nacional-desarrollistas, enfocadas en una economía que tenía como fin implementar un desarrollo hacia adentro, y erradicar no solo a las personas de manera individual, sino que también a los distintos "estratos sociales, de los Estados, sistemas políticos, sindicatos y centros académicos” (p. 41), y la única estrategia que en ese entonces se consideró para llevarlo a cabo fue la del "arrasamiento combinado (shock de exterminio), que dejaba el te-

1 La cursiva es mía. 
rreno social apto para la implantación del sistema neoliberal en estado puro (shock constituyente), generando así el nuevo sistema y la «nueva» memoria social" (Salazar, 2013, p. 41). El Triple Shock actuaba entonces:

Actuaba como un tridente, sobre tres planos: a) el humano (implantación, por medio de la violencia letal, de la indispensable "seriedad de la muerte"; b) el económico (imposición, por decreto militar simple, de las aristas extremas del mercado en estado puro), y c) el constituyente (imposición tiránica de una constitución política de camarilla, calcada de los intereses generales y particulares del capital financiero mundial). (Salazar, 2003, p. 43)

En este sentido, la implementación de un nuevo "orden", mediante el Triple Shock, trajo consigo consecuencias importantes y devastadoras para la mayoría del pueblo de Chile, en las que, a través de las demandas expuestas, queda al descubierto la injusticia y la desigualdad.

De esta manera, se podría pensar, a través de Freud (1992), que el malestar en la cultura surge a raíz de la condición de la renuncia del sujeto a sus pulsiones, lo que le permitiría vivir en comunidad con la condición de que la cultura le garantice dos cosas: "la protección del ser humano frente a la naturaleza y la regulación de los vínculos recíprocos entre los hombres" (Freud, 1992, p. 88); sin embargo, en Chile, lo que queda expuesto eran justamente condiciones en las que no existían ni se aseguraban los recursos simbólicos para que cada sujeto se las pudiera arreglar posteriormente, con su propia pulsión (Vernazza, 2018). Ya en 1927, Freud, en El porvenir de una ilusión, afirmaba:

Si una cultura no ha podido evitar que la satisfacción de cierto número de sus miembros tenga por premisa la opresión de otros, acaso de la mayoría (y es lo que sucede en todas las culturas del presente), es comprensible que los oprimidos desarrollen una intensa hostilidad hacia esa cultura que ellos posibilitan mediante su trabajo, pero de cuyos bienes participan en medida sumamente escasa. Por eso no cabe esperar en ellos una interiorización de las prohibiciones culturales; al contrario: no están dispuestos a reconocerlas, se afanan por destruir la cultura misma y eventualmente hasta por cancelar sus premisas. (Freud, 1992, p. 12)

Los elementos anteriores permiten ir pensando, al menos teóricamente, cuáles factores se fueron anudando junto a un malestar social 
que, como hemos visto, desembocaron en la revuelta social de octubre, ante las precarias condiciones de vida que vuelven hostil a la cultura misma, siendo esta un intento por cancelar sus premisas.

En ese sentido, la movilización social tendió a ser masiva. Por ejemplo, la marcha del 25 de octubre, que convocó a más de un millón de personas ${ }^{2}$ (El Desconcierto, 2019a). Y ante los distintos tipos de movilizaciones en las calles, a lo largo de todo Chile, la respuesta del gobierno estuvo caracterizada por el ejercicio de la violencia: evidenciando un aumento de la estrategia policial represiva y la persecución política, buscando con esto restringir el derecho a reunión ${ }^{3}$. Cabe destacar que estos hechos de violencia son a todas luces visibles, sistemáticos y generalizados, siendo un gran número de personas víctimas, y encontrándose entre ellas no solo manifestantes adherentes a la revuelta, sino que también personas que, por diferentes razones, se encontraban, vivían e incluso trabajaban allí. De acuerdo con el Instituto Nacional de Derechos Humanos (2020), las fuerzas de seguridad del Estado - Carabineros de Chile, Policía de Investigaciones y Fuerzas Armadas- habrían ejercido tortura, violencia física, detenciones ilegales, abusos y tortura sexual, daños oculares irreparables a más de 400 manifestantes e incluso una parte de este grupo perdió la vista en ambos ojos(INDH, 2019). Ante esta verdad visible el Estado desmiente lo ocurrido, que está frente a nosotros, pero algo lo hace o intenta hacerlo inaprehensible de ver. A esto le llamaremos más adelante una "política denegatoria", una política cuya función está en sostener que $l o$ que pasó no pasó (Davoine y Gaudillière, 2011).

Por lo recién expuesto es que surge la idea de plantear este texto, como reacción frente a un mecanismo que en psicoanálisis se conoce como uno de los elementos característicos de la perversión o, más bien, de la estructura perversa, a saber, la "desmentida".

De este modo, los conceptos anteriores tienen su origen y pertinencia en el hecho clínico y, por tanto, es un desafío complejo hacerlos

2 Los históricos registros que dejó “La Marcha Más Grande de Chile”. El Desconcierto (2019, 25 de octubre). Recuperado de https://www.eldesconcierto.cl/2019/10/25/loshistoricos-registros-que-dejo-la-marcha-mas-grande-de-chile/

3 Gobierno presentará proyecto para regular el derecho a reunión ciudadana. El Mostrador (2020, 12 de enero). Recuperado de https://www.elmostrador.cl/dia/2020/01/12/ gobierno-presentara-proyecto-para-regular-el-derecho-a-reunion-de-la-ciudadania/ 
trabajar en el orden de lo social - sosteniendo que esta es una de las limitantes del psicoanálisis-, teniendo en cuenta que conceptos fundamentales, tales como "inconsciente", "transferencia", "pulsión", "repetición" o "síntoma" (Lacan, 2015), al ser utilizados en otro campo, solo pueden usarse en sentido lato, es decir, perdiendo su especificidad clínica. Por tanto, habrá que aclarar que el término "desmentida" será utilizado no desde su particularidad clínica, sino como un modo de funcionamiento que permite pensar acerca de lo ocurrido en Chile y, sobre todo, del uso desmedido de este mecanismo por parte del Estado. Es por esto que, se advierte al lector o lectora que, a partir de ahora, el lenguaje será propio del psicoanálisis.

Una propuesta para este trabajo es pensar que, parafraseando a Gaudillière, las represalias psíquicas tomaron el carácter de una situación totalitaria en su dimensión traumática, invadiendo así todos los espacios de nuestra subjetividad, irrumpiendo de manera abrupta por cada ventana de nuestro psiquismo (Gaudillière, 2010, citado en Aceituno, 2010). En este caso, lo traumático no corresponde a la revuelta que estalla el 18 de octubre, sino más bien a la política represiva y brutal desplegada en las calles desde entonces hasta marzo del presente año. En este contexto, resulta importante poder pensar en las implicancias que tiene o podría tener todo esto en nuestra práctica clínica, pensando en un psicoanálisis posible, tal y como es pensado, con la rigurosidad técnica que ello implica, bajo las condiciones de que, a partir de octubre, si bien algo comenzó, también hay algo que se detuvo.

Llegados a este punto, resulta necesario plantear la pregunta sobre si es siquiera posible pensar la cuestión de la técnica en psicoanálisis como inalterable, cuando todo es - forzosamente- distinto. Para los efectos de este artículo esta problemática está centrada en la cuestión de la técnica, cuestión al menos ya esbozada como una crítica por Lacan (2005), en su conferencia de 1953 titulada "Lo simbólico, lo imaginario y lo real", a propósito de lo que concebía como una degradación en la misma. Sin embargo, existen muchos más elementos de la clínica psicoanalítica que son susceptibles de ser pensados y repensados a la luz de las circunstancias en que este texto se enmarca, vale decir, tiempos caracterizados por una política denegatoria, donde el destino de una irrupción traumática pareciera ser posible. 
El objetivo de este trabajo busca problematizar dichos elementos que son constitutivos para nuestra clínica, intentando dar relevancia a las preguntas y fundamentos de lo pertinente que sería cierta rigidez técnica o, al menos, su incuestionabilidad - sin desconocer el indudable valor teórico y clínico que la soporta- cuando el escenario social está organizado de tal forma que pareciera ser una necesidad, al menos, pensarlo para proponer finalmente ciertas variaciones técnicas, buscando garantizar dar lugar a aquella verdad que intenta ser borrada. Lo anterior se formalizará a partir de un recorrido teórico psicoanalítico, revisando cuestiones tales como la noción de "desmentida" en la perversión (neurótica y estructural), para posteriormente ir pensando los elementos de la realidad contextual junto a sus mecanismos e implicancias en el psiquismo, no solo del sujeto propio del psicoanálisis, sino que también de la subjetividad del sujeto de la cultura, siendo esta una de las directrices para pensar, finalmente, como una opción, ciertas variaciones en la técnica cuando lo que irrumpe en la clínica dista de tener que ver solo con el objeto psicoanalítico, sino que también con algo que excede las condiciones básicas para que se articule o sostenga el lazo social, una situación en la que, si bien seguimos siendo convocados en un lugar transferencial, también estamos atravesados, excedidos y convocados como sujetos de lo social frente a la misma situación traumática.

\section{Sobre la desmentida y la perversión}

Cuando Freud (1992), en su texto sobre el fetichismo, se refiere sobre el mecanismo de la desmentida en el fetiche, retoma el momento en que el niño, varón, se entera por una percepción de que la mujer no posee pene. En aquel momento la percepción permanece, sin embargo, también "se emprendió una acción muy enérgica para sustentar su desmentida" (Freud, 1992, p 149). En aquel momento, siguiendo a Freud, no se trata de que el infante haya guardado aquella percepción en la que sostiene que la mujer sí tiene falo, sino que la ha conservado pero también la ha resignado: tiene que sostener ambas posiciones, lo que sabe y que desmiente, esto a razón de que, si se enfrenta a ella - a la castración femenina-, lo que se pondría en juego sería la posibilidad y la verdad de su propia castración. Años más tarde Freud retomará la cuestión del fetiche en Esquema del psicoanálisis (1991), señalando que este podría aparecer como una formación de compromiso, con 
ayuda de un desplazamiento de algo que seguramente fue visto en el momento que fueron vistos los genitales femeninos, cuyo fin sería destruir la prueba de posibilidad de la castración.

Siguiendo esto, Freud (1991) sostendrá que

Así como el yo infantil, bajo el imperio del mundo real-objetivo, tramita unas exigencias pulsionales desagradables mediante las llamadas represiones. Y completémoslo ahora mediante esta otra comprobación: que el yo, en ese mismo periodo de la vida, con harta frecuencia, da en la situación de defenderse de una admonición del mundo exterior sentida como penosa, lo cual acontece mediante la desmentida de las percepciones que anotician de ese reclamo de la realidad objetiva. (p. 205)

Lo anterior podría permitir pensar en una diferencia entre mecanismos psíquicos, tales como la represión y la desmentida. La primera nos hace pensar en el modo en que el aparato psíquico se las arreglará, a través de esfuerzos de desalojo, con aquellas exigencias pulsionales internas que puedan resultar displacenteras para el psiquismo a través de la represión o esfuerzos de desalojo. Sin embargo, para pensar la desmentida nos es útil pensar la relación que existirá con el mundo externo que, de algún modo, pueda también resultar penoso. Leonardo Peskin (2015), a partir de la lectura de Lacan, esclarece una distinción entre dos mecanismos psíquicos distintos - en dos estructuras psíquicas, la neurosis y la perversión-: siendo los mecanismos la negación y la desmentida respectivamente. La primera, la negación, busca contribuir al desconocimiento de algo que supone haber sido percibido y que no se quiere saber nada de esa percepción, sosteniendo de este modo la represión, un ejemplo claro es el que usa Freud cuando explica la negación: "Usted pregunta quién puede ser la persona del sueño. Mi madre no es” (Freud, 1992, p. 253). Por otro lado, la desmentida excluirá la percepción o, mejor dicho, aquella verdad que se impone junto a su inscripción inconsciente, siendo una tarea de exclusión simbólica de un elemento que podría estar en relación y/o conexión con algo de lo cual no se quiere saber nada.

Para retomar la última idea del párrafo anterior, podríamos pensar, a propósito de una clínica estructural de la perversión, donde la estructura se define, según Lacan (En Eidelsztein, 2008, p. 49) como un "conjunto co-variante de elementos significantes". Podemos ver que la 
posición ante la cual se encuentra el sujeto de una estructura perversa es difícil de sostener, Thibaut e Hidalgo (2004) refieren, a propósito de esta verdad, que

A pesar de que los hechos le muestran a cada momento que la mujer está castrada, él tiene que seguir sosteniendo lo contrario; para no ser delirante, el perverso requiere que los demás compartan su creencia, con lo que se puede pensar que la fantasía fundamental de la perversión es que el otro es pervertible, es decir, que puede llegar a compartir su posición respecto de la castración. (p. 239)

De este modo, el sujeto perverso ha de mostrarse como aquel que sabe cómo se goza (para causar atracción sobre los ojos de cualquier neurótico, al cual buscará cautivar para compartir su creencia), de modo que el requerimiento lógico que se le impondrá será hacer que el otro "goce de la posición en la que él mismo le ha colocado" (Thibaut e Hidalgo, 2004, p. 240), es decir, el otro aparecerá como alguien pervertible 0 , mejor dicho, alguien a quien se puede pervertir.

\section{Política denegatoria y horizontes de lo traumático}

Como se señaló, desde el comienzo de la revuelta social en Chile el clima político estuvo marcado por conflictos en las calles, caracterizados, por una parte, por la represión por parte de la fuerza policial del Estado - disparo de perdigones y bombas lacrimógenas al cuerpo de manifestantes, gases lacrimógenos con altos niveles de toxicidad y peligro para la salud, choques a manifestantes, carros lanza agua siendo lanzada, mutilación de ojos, abusos de poder, abusos sexuales, etc.- $\mathrm{y}$, por otra, por el uso de la desmentida ante lo que ocurría hasta marzo del 2020, haciéndose uso de la violencia de Estado como medio para justificar aquello que se estaría desmintiendo.

Para esto quizá sea importante recordar uno de los primeros informes preliminares que fueron emitidos por el equipo de Amnistía Internacional, luego de realizar una investigación sobre cómo se había desarrollado el conflicto político y social en Chile en materia de derechos humanos. Este informe, emitido el 21 de noviembre del 2019, indicaba que

Las fuerzas de seguridad bajo el mando del presidente Sebastián Piñera - principalmente el Ejército y Carabineros (la policía nacio- 
nal) - están cometiendo ataques generalizados, usando la fuerza de manera innecesaria y excesiva con la intención de dañar y castigar a la población que se manifiesta. Estos ataques han dejado hasta el momento un saldo de cinco muertos y miles de personas torturadas, maltratadas o gravemente lesionadas. (Amnistía Internacional, 2019, p. 1)

Frente a estas declaraciones, durante esa misma jornada, personal del gobierno se encargaría de rechazar categóricamente dicho informe, indicando que "sin siquiera solicitar información al gobierno, pretende establecer la existencia de una política deliberada para dañar a los manifestantes. La única política que ha tenido el gobierno es la del resguardo y protección de los derechos humanos" (Recabarren, 2019 en Andrews, 2019), lo que Amnistía Internacional desmentirá dando y mostrando como prueba la carta que le había sido enviada al presidente y de la cual no obtuvieron respuesta alguna, según indica CNN.

Cinco días después, el 26 de noviembre del 2019, Human Rights Watch emitía un informe en el cual declaraba que Carabineros han disparado cartuchos de gases lacrimógenos directamente hacia los manifestantes, ha habido - hasta el 21 de noviembre- 442 querellas ante el Ministerio Público, de víctimas con presuntas lesiones ejercidas por Carabineros por tratos crueles, violencia sexual (por ejemplo la obligación de desvestirse y hacer sentadillas desnudos en comisarías, incluyendo infantes), tentativa de homicidios y homicidios. La Defensoría de la Niñez — hasta esa fecha- habría recabado 327 casos de posibles violaciones de derechos de niños y niñas durante las manifestaciones entre el 18 y 25 de octubre (Human Rights Watch, 2019).

Como estos, son muchos los ejemplos que refieren sobre el lugar de la política denegatoria, aquella que no da lugar a una verdad de la cual toma noticia, de la cual sabe y que luego se encargará de desmentir. Otra noticia importante, emitida el 6 de diciembre del 2019, era dada por el Colegio de Químicos Farmacéuticos y Bioquímicos de Chile, a través de un análisis que habría realizado el Movimiento Salud en Resistencia, cuyo resultado fue que, dentro de los componentes utilizados por el carro lanza aguas, no solo existía gas pimienta, sino que también soda cáustica, componente que sería la causa de un gran número de quemaduras graves en la piel en un gran número de manifestantes (Leiva, 2019). Antes de que este informe fuese entregado formalmente 
- el cual ya era de conocimiento público-, un día antes el general de Carabineros Mario Rozas declaraba, en el programa de TV Mesa Central de Canal 13, que "las quemaduras provocadas a manifestantes son producto de enfermedades preexistentes" (Miranda, 2019), para que al día siguiente, siendo ya público el informe, él mismo lo negara bajo la

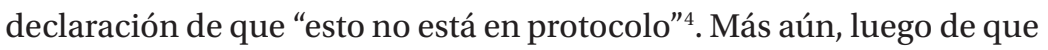
se difundieran las imágenes el 20 de diciembre, en las que se veía un carro lanza gases que chocaba y embestía a un manifestante, con clara intención, dejándolo apresado entre dos de estos vehículos ${ }^{5}$, desde la propia institución salía a declarar el general Enrique Monras, diciendo que "en forma temeraria un joven encapuchado se cruza en la trayectoria de ambos vehículos" ${ }^{\prime \prime}$. Dado esto, resulta inevitable pensar, por una parte, en la evidente desmentida o denegación frente a un hecho real, y, por otra, en algo que Davoine y Gaudillière (2011) definen como "perversión del juicio", en la cual "las víctimas son las culpables y viceversa” (p. 22).

Los ejemplos anteriores fueron elegidos principalmente por lo que podría pensarse como la vía o la acción denegatoria sobre el saber y la verdad. Sobre la primera, porque fueron hechos constatados, denunciados y entregados por instituciones del aparato público, que tienen un respaldo por su credibilidad y que fueron creados después de hechos históricos donde se han violaran gravemente los derechos humanos en Chile (la Defensoría de la Niñez o el Instituto Nacional de Derechos Humanos, por ejemplo): ellas entregaron el número de denuncias acogidas, junto también a los hechos que instituciones tales como Amnistía Internacional y Human Rights Watch habrían observado y recopilado para elaborar dichos informes. Sobre la segunda, porque sobre algo ya sabido y conocido nada era reconocido.

4 Carabineros niega el uso de soda caustica en el carro lanza agua: "no está en los protocolos". T13 (2019, 16 de diciembre). Recuperado de https://www.t13.cl/noticia/nacional/carabineros-niega-uso-soda-caustica-carro-lanza-agua-no-esta-protocolos

5 Amnistía Internacional desmiente al gobierno y publica carta en que solicitó reunión con Piñera por DD.HH. CNN (2019, 22 de noviembre). Recuperado de https://www. cnnchile.com/pais/amnistia-internacional-carta-reunion-pinera-dd-hh_20191122/

6 Carabineros asegura que joven atropellado en Plaza Dignidad se cruzó de manera "temeraria" en la trayectoria de los vehículos. El Desconcierto (2019, 22 de diciembre) Recuperado de https://www.eldesconcierto.cl/2019/12/22/carabineros-asegura-quejoven-atropellado-en-plaza-de-la-dignidad-se-cruzo-de-manera-temeraria-en-la-trayectoria-de-los-vehiculos/ 
Sin duda que los hechos exceden a los ya presentados. Solo por nombrar algunos más nos encontramos con los dichos del presidente Sebastián Piñera, afirmando que muchos de los videos viralizados en las distintas plataformas digitales sobre violaciones a los derechos humanos son "falsos, filmados fuera o tergiversados" (Piñera, 2019 en Cooperativa, 2019)7 ; por otra parte, la ministra de la Mujer y la Equidad de género - en ese entonces Isabel Plá-señalóaba que, durante el periodo en que se desarrolló la revuelta social, no ocurrieron violaciones a los derechos humanos de mujeres (González, 2020). Sin duda, ambos ejemplos pueden ser desdichos con las estadísticas entregadas por el INDH, en las cuales las cifras dictaminan elementos totalmente contrarios a lo afirmado desde el gobierno (INDH, 2019) ${ }^{8}$.

De este modo se vuelve necesario pensar, primero, en las condiciones de continuidad de un psiquismo que se ha visto enfrentado al detenimiento, interrupción o irrupción de lo traumático en el país. Considerando a su vez los planteamientos de Davoine y Gaudillière (2011), cuando la Gran Historia, aquella historia de las sociedades, que nos atraviesa y que también nos antecede, es desmentida, resultaría un tanto complejo darle un lugar en la historia, la cual es singular y atravesada desde los propios conflictos con nuestros fantasmas, y así lograr un acto de inscripción psíquica tomando a Bion (1990), cómo podría ser siquiera pensable crear las condiciones para metabolizar aquellas experiencias en bruto o elementos beta que quedan circulando, para así constituir un aparato que sea capaz de poder pensarlos o, también, sobre aquel soporte "narcisizante" en que el Otro pueda proveer las condiciones necesarias para que pueda ser pensable un trabajo de memoria y de olvido posible (Aceituno, 2010), frente a un esfuerzo evidente de intentar buscar que algo no sea inscrito, dicho ni recordado. Aquí podríamos pensar el lugar que toma el psicoanálisis, al pensar que cualesquiera sean los intentos, siguiendo a Davoine y Gaudilliére (2011), de borrar o erradicar hechos de la memoria, lo que se pone en

7 Piñera: "Muchos videos sobre violaciones a DD.HH son falsos, filmados fuera o tergiversados". Cooperativa, (2019, 26 de diciembre). Recuperado de https://www.cooperativa.cl/noticias/pais/manifestaciones/pinera-muchos-videos-sobre-violaciones-addhh-son-falsos-filmados/2019-12-26/013433.html

8 Para acceder a la infografía revisar el siguiente enlace: https://www.indh.cl/bb/wpcontent/uploads/2019/12/12.30-acciones-judiciales.jpg 
marcha es una "memoria que no olvida" y que busca las vías para su inscripción, que quiere ser inscrita.

Si pensamos esta situación totalitaria — no en tanto totalitarismo, sino más bien en su dimensión invasiva que irrumpe en cada espacio de nuestra subjetividad—, resulta necesario pensar en nuestra práctica analítica, sobre todo cuando las posibilidades y condiciones de trabajo están marcadas y atravesadas por la violencia política, una violencia vivida, sufrida y testificada por un gran número de ciudadanas y ciudadanos a manos de las fuerzas de seguridad del Estado, ejerciendo por ejemplo tortura, violencia física, detenciones ilegítimas, abuso y tortura sexual, daños oculares, etc. (INDH, 2020). Frente a esto, resulta necesario al menos pensar en las condiciones para que un psicoanálisis, tal y como lo conocemos, sea posible.

Por lo mismo, cabría al menos preguntarnos si incluso el lugar del Otro, en el que somos ubicados en la transferencia, también estaría sumergido en este contexto - haciendo una metáfora de la inmersión o invasión traumática que ocupa el lugar de la violencia estatal en nuestras subjetividades - ante la función denegatoria de la política, la función de la misma entonces sería poner en práctica "una tentativa de borramiento de aquello que, 'habiendo sido vivido realmente' bajo la forma del derrumbe y de la desaparición forzada, no podría tener lugar" (Aceituno, 2010, p. 79). Y no podría tener lugar en la medida que el objetivo de tal empresa sería "no dejar huellas" y esta política, al ser denegatoria, será, sin duda, también perversa.

\section{Sobre el encuadre y la inmersión totalitaria}

Freud (1991), además de señalar que la posición analítica implica que él o la analista "no debe ser transparente para el analizado, sino, como la luna de un espejo, mostrar solo lo que le es mostrado" (p. 117), también sostiene que dentro de los elementos centrales para posibilitar un trabajo psicoanalítico se encuentran la atención parejamente flotante, la neutralidad y la regla de abstinencia. Sobre la primera, la atención parejamente flotante, Freud (1991) decía

...no sé cómo encarecería bastante a mis colegas que en el tratamiento psicoanalítico tomen por modelo al cirujano que deja de lado todos sus afectos y aun su compasión humana, y concentra 
sus fuerzas espirituales en una meta única: realizar una operación lo más acorde posible a las reglas del arte. (p. 114)

Y prosigue

Aquella frialdad de sentimiento que cabe exigir del analista se justifica porque crea para ambas partes las condiciones más ventajosas: para el médico, el muy deseable cuidado de su propia vida afectiva; para el enfermo, el máximo grado de socorro que hoy nos es posible prestarle. (pp. 114-115)

Esto supone que cada contenido elaborado por cada paciente ha de ser considerado por igual, de la misma importancia, suspendiendo así cualquier tipo de juicio por parte del analista. De esto último se desprende lo que refiere al principio de neutralidad, en cuanto a que el analista ha de abstenerse "en cuanto a los valores religiosos, morales y sociales, es decir, no dirigir la cura en función de un ideal y abstenerse de todo consejo" (Laplanche \& Pontalis, 2004, p. 256). La neutralidad supondrá también desproveerse de ideales que pudiesen orientar la cura analítica, y esto último nos permitirá pensar sobre la regla de abstinencia, la cual supone que el analista no satisfaga las demandas, tanto explícitas como implícitas, además de no desempeñar los papeles en los cuales se es puesto transferencialmente.

Tras haber hecho un recorrido breve por ciertos elementos del encuadre analítico, resulta importante pensar acerca de la inmersión totalitaria, para esto quisiera tomar una cita de Jean-Max Gaudilliére (2010), a propósito de un paciente que soñaba, con horror, que por doquiera que mirara ningún departamento tenía muros; el sueño databa de 1934 y Hitler acababa de procurarse los medios legales para comenzar oficialmente su proyecto totalitario. La cita refiere que "en Alemania, ya no hay asuntos privados. Si usted se duerme, ese es su asunto privado, pero desde el momento en que despierta y entra en contacto con otra persona, debe recordar que es soldado de Adolf Hitler..." (p. 87). La cuestión de la inmersión es posible de pensar como una metáfora de lo líquido, de la inmersión de un cuerpo en un líquido, salvo que, en estos casos, al hacer una analogía de lo totalitario, sería el cuerpo siendo adentrado por algo que lo atraviesa, el cuerpo siendo arrastrado por una gran ola, algo así como la Gran Historia atravesando e irrumpiendo sobre la serie de historias particulares. 
A partir de la revuelta social del 18 de octubre, podríamos pensar el estatuto traumático que irrumpe en nuestro psiquismo como efecto de la violencia política y represiva del Estado de Chile. Sobre esto Aceituno (2019) lo referirá como aquella situación en la que el totalitarismo entra por la ventana, invadiendo todo, salvo un rincón que pareciera resistirse, siendo este el lugar del dormir y del soñar. Lo difícil de sostener es el valor no metafórico de estas palabras, si consideramos que lo que invade este funcionamiento loco del lazo social no son solo los espacios comunes (el contingente policial desplegado en los distintos rincones de la ciudad), sino también nuestro psiquismo y en los espacios más íntimos, tales como nuestras consultas con nuestros pacientes (escuchando y viviendo protestas fuera de ella, la policía disparando, alzamiento de barricadas y sus restos, sirenas de carros policiales que van y vienen, etc.). Difícilmente en estas circunstancias podríamos pensar en los modos de funcionamiento de la realidad psíquica del modo habitual con el cual acostumbramos a trabajar, sino más bien, siguiendo a Aceituno y Cabrera (2014), podríamos pensar que esta situación - que podríamos calificar de "traumática" - interrumpe las vías habituales de elaboración porque, también, es el lazo social en el que el sujeto se desenvuelve el que se ve interrumpido o, más bien, avasallado.

Frente al enloquecimiento del lazo social y la política denegatoria, lo que propongo pensar guarda relación con ciertas distinciones en la técnica psicoanalítica, cuando por lo que somos atravesados o convocados puede exceder lo que supondría el lazo transferencial. Hay algo ahí afuera por lo cual también somos convocados, la Gran Historia para analista y paciente es la misma y a la vez distinta, la misma en cuanto a sujetos de lo social (o de las ciencias sociales) y distinta porque la misma estará atravesada por los propios fantasmas inconscientes (del sujeto psicoanalítico): la pequeña historia. Sin embargo, justamente en ese pequeño espacio - entre la Historia y la historia- es donde podríamos pensar que lo que se pone en juego no corresponde únicamente a elementos contratransferenciales por aquellos determinantes inconscientes que se ponen en juego en la situación analítica, y, al parecer, es en ese espacio donde podríamos pensar ciertas variaciones de la técnica analítica por la excepción que también supondrá las variaciones en el lazo. 


\section{Frente al enloquecimiento del lazo social y la política denegatoria ¿variaciones en la técnica?}

Como ya revisamos, el lugar de los elementos que componen el encuadre en psicoanálisis tiene como función, valga la redundancia, el generar las condiciones de cierto tipo de trabajo, a saber, un trabajo psicoanalítico y, en ese caso, lo que se definirá será un método en específico: cierto tipo de escucha, cierta dirección de la cura, cierto objeto también definirán lo que es un/a analista y también lo que será un/a paciente, etc.

En cierto espacio clínico la conversación giraba en torno a lo siguiente, que las condiciones de trabajo eran mucho más simples de seguir y de trabajar cuando las cosas fuera de la consulta tenían cierta estabilidad; sin embargo, la dificultad se presenta cuando lo que pasa afuera se desestabiliza. Davoine y Gaudilliére (2011) decían que "la locura resquebraja las certezas mejor fundadas" (p. 50). No existen dudas de que el valor teórico de la técnica psicoanalítica tiene sustento y valor clínico; sin embargo, cabría preguntarse si es posible hacer ciertas variaciones a la técnica cuando el lazo social está enloquecido y la política tiende a ser denegatoria. ¿Si hay variaciones necesariamente se estaría fuera del terreno de lo psicoanalítico? Sin duda que, por ejemplo, si introducimos elementos de la realidad social estaríamos lejos del ideal de trabajar/funcionar como la luna de un espejo e, incluso, posibilitando elementos que podrían transparentar nuestra propia posición - por ejemplo, transmitir ciertos ideales que tengan cierto impacto en el lazo transferencial y, así, alejarnos de la regla de la neutralidad-, trayendo lo social al diván habría que tener especial atención y discreción, bajo el supuesto de que la angustia provocada por lo social - y que sin duda afectará a cada sujeto desde su propios conflictos- está paralelamente actuando junto a la angustia neurótica.

Lo que propongo es que, al hacer ciertas variaciones en la técnica, es importante saber que, sea cual sea el tipo de intervención que se elija, ésta tendrá ciertos efectos. Traer lo social a la consulta también como una intervención ante "la explosión, sin metáfora, de las garantías de la palabra” (Davoine \& Gaudilliére, 2011. p. 38) para posibilitar no solo reconstruir en la transferencia garantías que parecieron perderse (y que insisten en buscar una vía para su inscripción), sino que también dar lugar a aquello que se deniega y que sin embargo siempre 
está ahí. Ante el esfuerzo de borramiento estatal buscar, en la clínica, zonas de no existencia que exploran su inscripción haciendo de la experiencia analítica su función épica: enfrentarse a decir lo inaudito (Davoine y Gaudillière, 2011), hacer de la experiencia analítica también un lugar de verdad.

\section{¿Qué variaciones?}

Al pensar en variaciones en la técnica, pienso en ellas también por su carácter de excepción, a saber: la excepción hizo pensable algo que antes no había sido del todo cuestionado o al menos necesario de cuestionar. Y respecto de la excepción, de lo que se trató fue de ir pensando en el qué hacer desde la estructura clásica de la clínica psicoanalítica, por ejemplo, pensar en ciertos momentos sobre la regla fundamental establecida entre analista y paciente para librar a la misma de cualquier sugestión, siendo a veces incluso necesario. Por otra parte, incluso cuestiones mucho más prácticas, tales como llamar o no a cada paciente - no solo por faltas reiteradas, por ejemplo—; en qué momento, escribirles preguntándoles por su bienestar, mostrar cierta disponibilidad distinta ante lo que ocurre en lo social; cuestiones tales como el levantamiento del toque de queda, pacientes con participación activa en las manifestaciones, pacientes a quienes les evocaba altos montos de angustia todo lo que ocurría; dificultades en la vuelta a casa por los cortes de tránsito y, también, por la propia preocupación que por ellos sentía - sin duda habrá que pensar los elementos inconscientes que puedan ponerse o no también en juego, al aparecer de carne y hueso-.

La cuestión de lo social me hizo interrogar elementos del psicoanálisis para pensar la clínica, por ejemplo — parafraseando a Bion y reconociendo la distinción clínica y lo apuntado en su propuesta-, ¿cómo posicionarse sin memoria y sin deseo (Bion, 1969) en la escucha? ¿Cómo pensar que todo lo dicho suponía solo elementos inconscientes, actualizándose en la transferencia, cuando había un exceso de realidad que irrumpía e invadía cada espacio? Ante esto se fue posibilitando pensar intervenciones que incluyeran la realidad y sus vicisitudes, por ejemplo, introducir la realidad $-\mathrm{y}$ reconocerla - para pensar el fenómeno de la violencia, específicamente la diferencia de estatuto de la violencia desde quienes representaban al Estado y desde los que se enfrentaban a ella de forma reivindicativa, en pacientes que 
han atravesado innumerables episodios de violencia y que, desde ese lugar, también les parecía difícil diferenciarla por la confusión que la misma suponía - violencia que sin duda no es la misma ni es igual一, que incluso podría hacer pensar en la función de Reverie propuesta por Bion (1990); por otra parte, también trabajar con pacientes con fantasías mucho más persecutorias ciertas distinciones en la angustia suscitada: trabajar la angustia real propiciada como efecto de lo que ocurría allí afuera, reconocerla para distinguirla de la angustia neurótica, por ejemplo, y también ver cómo, en ciertos episodios, una se anudaba a la otra.

La irrupción de la realidad también supuso ciertas modificaciones, como también ciertas dificultades; por ejemplo, al flexibilizar horarios - por el difícil acceso a la consulta en transporte público que se paralizaba-, dado que en ese entonces aún no era condición sine qua non atender de manera digital, por la dificultad de volver al hogar tanto de pacientes como mía, entre otras. Por cuestiones que nos convocaban en el mismo lugar en cuanto a sujetos sociales, de carne y hueso, y todo esto propiciaba el pensar otras cuestiones que se ponían en juego, tales como el cobro: cómo cobrar cuando las condiciones ya no eran las mismas, cuando efectivamente lo impredecible del clima social impedía ciertas certezas respecto del traslado y, a su vez, cómo pensar el cobro cuando la misma imprevisibilidad del clima social podía permitir hacer uso del mismo como una resistencia inconsciente, cuestiones que sin duda podrán ser trabajadas en una sesión de análisis no por ello sin sus vicisitudes.

Todas estas vicisitudes irán dando respaldo al valor de la técnica y de la teoría que soportan a una clínica; sin embargo, pareciera que se van tensionando - o habría que tensionarlas- cuando las condiciones de trabajo no son las ideales, sino que son excepcionales.

\section{Reflexiones y conclusiones}

Las reflexiones que orientaron este texto dejaron más preguntas que respuestas y, sin embargo, resulta importante a lo menos pensar sobre nuestra propia práctica en estas condiciones y preguntarnos, desde ese lugar, si acaso será posible pensar ante una realidad que nos invade hasta en los espacios más íntimos, como diría Bion (1967) sin memoria y sin deseo. La neutralidad, como elemento técnico en la clínica, frente 
al cuestionamiento de perderla en un contexto como el que se ha vivido en Chile, siguiendo a Biason (2013), que al no lograr incluir la realidad social en la tranquilidad de la consulta, ise podría llegar, incluso, a ser cómplice de lo real de una violencia de Estado? que éste, a través de sus distintos mecanismos de poder ejerce a través de sus discursos oficiales y, así, me atrevería a decir, ser cómplice de su misión perversa (Sinatra, 2008 en Miller, et al, 2008). ¿Puede ser posible, pensando en su reverso, sostener una posición analítica más neutral que en cualquier otro momento? Al no hacer parte lo social en la consulta -y saber distinguirlo de lo que nos convoca la clínica- o no dejar que entre porque lo que nos interesaría serían solo los elementos inconscientes puestos en juego, ¿sería acaso denegar también una parte de la realidad?

Quizás, sería conveniente seguir las ideas de Aceituno y Cabrera (2014), a propósito de que la atención libremente flotante de la escucha del analista es el anverso de la función de historiador, es decir, de aquel que resguarda los archivos — siguiendo a Green - fragmentados y a veces mudos, que tendrá que sostener en el lazo transferencial hasta darle forma y lugar. En este contexto, toma vital importancia cuando es una historia, una verdad que insiste en no querer ser contada.

Sin duda que hacer y pensar ciertas variaciones en la técnica supondrá efectos en nuestra clínica, en nuestras intervenciones y en nuestros pacientes, porque algo de esas situaciones no inscritas buscará distintas vías de inscripción, tal como en el lazo transferencial. Sin embargo, también nos llevará a pensar el estatuto de cuestiones tales como qué pasará con aquellos pacientes que sin duda puedan pensar que no existe desmentida alguna, quienes no puedan pensarlo porque es algo que no puede ser pensado o que no existen las condiciones para hacerlo pensable, de una posición política distinta -que por cuestiones técnicas no debiese tomar relevancia alguna- y que en un contexto como este pongan ciertos elementos en tensión, no es todo, en este caso, una cuestión contratransferencial.

Para finalizar, resulta al menos importante plantear que cuando una política es denegatoria sin duda que su operatoria también tenderá a ser perversa y al hacer ciertos movimientos en la neutralidad para constatar aquello que busca ser borrado implica, por un lado, ocuparse de la tarea de que también el espacio analítico está soportado en uno de los lugares en los cuales es demandado, a saber, un 
lugar de verdad o mejor dicho de verdades. Por otra parte, al incluir lo social denegado - o sus intentos de inclusión- no implica necesariamente hacer variaciones - y a la vez una necesaria distinciónen la neutralidad, cuando esta es pensada como una función de la interpretación, es decir, cuando lo que circula se moviliza dentro del campo del deseo.

\section{Referencias}

Aceituno, R. (2019). Psicoanálisis y política hoy. Revista Gradiva, $\operatorname{VIII}(2)$.

Aceituno, R. (2010) Espacios de tiempo: Clínica del traumatismo y procesos de simbolización. Santiago de Chile: FACSO Universidad de Chile.

Aceituno, R. \& Cabrera, P. (2014). Elementos introductorios para una clínica de lo traumático y su elaboración. En P. Cabrera (Compilador), Construcciones. Clínica de lo traumático y figurabilidad. Santiago de Chile: FACSO Universidad de Chile.

Andrews, J. (2019, 21 de noviembre). Gobierno rechaza categóricamente informe de Amnistía Internacional por violaciones de derechos humanos. La Tercera. Recuperado de https:// www.latercera.com/nacional/noticia/gobierno-rechazacategoricamente-informe-amnistia-internacional-violaciones-derechos-humanos/910797/

Amnistía Internacional. (2019, 21 de noviembre). Chile: Política deliberada para dañar a manifestantes apunta a responsabilidad de mando. Recuperado de https://www.amnesty.org/es/latest/news/2019/11/chile-responsable-politica-deliberadapara-danar-manifestantes/

Biason, L. (2013). Violencia de Estado y consecuencias psíquicas. Revista Liminales, 2(4), 115-125.

Bion, W. (1990) Volviendo a pensar. Buenos Aires: Hormé.

Bion, W. (1967). Notas sobre la memoria y el deseo. Revista Psicoanálisis, 26(3): 679-681. Recuperado de https://www.pep-web. org/document.php?id=revapa.026.0679a

Davoine, F. y Gaudillière, J. (2011). Historia y trauma. Las locuras de las guerras. Buenos Aires: Fondo de Cultura Económica.

Eidelsztein, A. (2008) Las estructuras clínicas a partir de Lacan. Buenos Aires: Letra Viva. 
Flisfisch, A. (1982). El neoliberalismo chileno: las funciones del dogmatismo. FLACSO: Santiago.

Freud, S. (1991). Consejos al médico sobre la iniciación del tratamiento. En Obras Completas. (Vol. 12, pp. 107-119). Buenos Aires: Amorrortu.

Freud, S. (1991). Esquema del psicoanálisis. En Obras Completas. (Vol. 23, pp. 133-210). Buenos Aires: Amorrortu.

Freud, S. (1992). El porvenir de una ilusión. En Obras Completas. (Vol. 21, pp. 1-55). Buenos Aires: Amorrortu.

Freud, S. (1992). El malestar en la cultura. En Obras Completas. (Vol. 21, pp. 57-140). Buenos Aires. Amorrortu.

Freud, S. (1992). El fetichismo. En Obras Completas. (Vol. 21, pp. 141152). Buenos Aires: Amorrortu.

Freud, S. (1992). La negación. En Obras Completas. (Vol. 19, pp. 249258). Buenos Aires: Amorrortu.

Gaudillière, J. (2010) Soñar en situación totalitaria. En R. Aceituno (Ed.), Espacios de tiempo: Clínica del traumatismo y procesos de simbolización. Santiago de Chile: FACSO Universidad de Chile.

González, A. (2020, 4 de marzo) Ministra Plá negó las violaciones a los DD.HH. de mujeres durante el estallido social. Biobio Chile. Recuperado de https://www.biobiochile.cl/especial/loque-debes-saber-hoy/2020/03/04/ministra-pla-nego-violaciones-a-los-ddhh-de-mujeres-durante-estallido-social. shtml

Human Rights Watch. (2019, 26 de noviembre). Chile: llamado urgente a una reforma policial tras las protestas. Uso excesivo de la fuerza contra manifestantes y transeúntes; graves abusos en detención. Recuperado de https://www.hrw.org/es/ news/2019/11/26/chile-llamado-urgente-una-reforma-policial-tras-las-protestas

Instituto Nacional de Derechos Humanos. (2019, 30 de diciembre). Infografía de acciones judiciales. Recuperado de https://www. indh.cl/bb/wp-content/uploads/2019/12/12.30-accionesjudiciales.jpg

Instituto Nacional de Derechos Humanos. (2020, 18 de febrero). Infografía de reporte hospitales. Recuperado de https://www. indh.cl/bb/wp-content/uploads/2020/02/02.18-hospitales.jpg 
Instituto Nacional de Derechos Humanos. (2020, 19 de marzo). Infografía de reporte hospitales. Recuperado de https://www. indh.cl/bb/wp-content/uploads/2020/03/INDH-PLANTILLA-POST-HOSPITALES-19-MARZO-2020.jpg

Lacan, J. (2005). Lo imaginario, lo simbólico y lo real. En De los nombres de padre. Buenos Aires: Paidós.

Lacan, J. (2015). El seminario de Jacques Lacan. Los cuatro conceptos fundamentales del psicoanálisis. Buenos Aires: Paidós.

Laplanche, J. \& Pontalis, J. (2004) Diccionario de Psicoanálisis. Buenos Aires: Paidós.

Leiva, F. (2019). Informe análisis determinación molecular y efectos fisicoquimicos. Recuperado de https://drive.google.com/ file/d/0B7vJuiYMbnNCNERUcUdRYmJZRVF2eFJVcDJqcGp KaHdCTTZR/view

Miller, J. et al. (2008) Psiquiatría y Psicoanálisis. Perversos, psicópatas, antisociales, carecterópatas, canallas. Buenos Aires: Ed Gramma.

Miranda, G. (2019, 15 de diciembre). Mario Rozas por denuncias de quemaduras: "Es cuando hay enfermedades preexistentes". ADN Radio. Recuperado de https://www.adnradio. $\mathrm{cl} /$ nacional/2019/12/15/mario-rozas-por-denuncias-dequemaduras-es-cuando-hay-enfermedades-preexistentes-3991460.html

Peskin, L. (2015). La realidad, el sujeto y el objeto. Buenos Aires: Paidós.

Salazar, G. (2013). Villa Grimaldi (Cuartel Terranova). Historia, testimonio y reflexión. Santiago de Chile: LOM.

Thibaut, M. y Hidalgo, G. (2004). Trayecto del psicoanálisis de Freud a Lacan. Santiago de Chile: Universidad Diego Portales.

Vernazza, D. (2018). Una democracia que no cesa de no escribirse. En R. Espina et al., Lacan en las lógicas de la emancipación. A partir de los textos de Jorge Alemán. Santiago de Chile: Pólvora Editorial. 